Research Article

\title{
Student's perception towards learning medical sciences: problem based learning versus lecture based learning methods
}

\author{
Padmanabha TS.*, Manu G., Madhav K. Savkar, Chandrakantha T., Neha K.
}

\begin{abstract}
Department of Pharmacology, Adichunchanagiri Institute of Medical Sciences, BG Nagara 571448, Nagamangala, Mandya, Karnataka, India
\end{abstract}

Received: 06 January 2016 Accepted: 03 February 2016

\section{*Correspondence to:}

Dr. Padmanabha TS.,

Email: padmanabhatsp@ gmail.com

Copyright: (C) the author(s), publisher and licensee Medip Academy. This is an openaccess article distributed under the terms of the Creative Commons Attribution NonCommercial License, which permits unrestricted noncommercial use, distribution, and reproduction in any medium, provided the original work is properly cited.

\begin{abstract}
Background: Problem-based learning (PBL) is one of the most commonly used educational methods in medical schools of different countries. By working through this method, students think critically, generate with ideas, and acquire the knowledge and skills required to become a doctor. The objectives were, this study aimed to compare problem-based learning with lecture-based learning in the education of medical students on different disciplines but addressing the 2 nd year subjects as a whole $\&$ in particularly pharmacology.

Methods: This cross-sectional observational study was conducted on medical students of Bidar Institute of Medical Sciences, Bidar. All the students were enrolled in the study were given with pretested questions after obtaining the institutional ethical clearance and informed consent from the students. Fully completed questionnaires were collected and analysed.

Results: Students preferred problem-based learning over lecture-based learning (LBL) because of motivation boost, a higher quality of education, knowledge retention, class attractiveness, and practical use. However, the difference was not statistically significant. Although PBL edged over LBL, but most of them preferred integrated teaching going side by side, i. e, PBL along with LBL.

Conclusions: Students' percieves that the knowledge \& understanding could be very easily acquired by PBL over LBL. Students felt Pharmacology should be taught with both ways, initially LBL followed by PBL for better understanding the concepts for clinical application.
\end{abstract}

Keywords: Teaching methods, PBL, Traditional based learning

\section{INTRODUCTION}

Problem-based learning (PBL) is one among the preferred educational methods in medical schools. In this method, students use scenarios to define their own learning goals and objectives. It's the quality of the scenarios which makes PBL successful. ${ }^{1}$ Presentation of clinical problems forms the initial platform for understanding PBL. By sincerely going through to solve these problems, student's starts thinking critically about the problems nature, generate ideas, and acquire the knowledge, skills and confidence required to become a responsible health care professionals. ${ }^{2}$ It is known that students will have better knowledge retention with this method $^{1}$ and PBL increases in-depth training, and helps students to perform better in examinations by having the overall insight in respective subjects. ${ }^{3}$ Although few supports that PBL acquires learning motivation is one of the benefits of this method, and other few mention that it is time-consuming and does not provide a better clinical competence. ${ }^{4}$ In LBL method, students entirely get the information from the class lecturer and try to memorize the content instead of understanding the concepts and using them. Therefore, at the patient's bedside, they unconsciously and merely satisfy themselves with the routine work, deal passively with new situations, and make no effort toward thinking and innovation to diagnose and meet the existing requirements. ${ }^{5}$ Many studies were conducted to compare PBL with the traditional LBL. With respect to acquiring knowledge, investigations showed different results. In some studies, PBL did not show any preference over LBL 
on the trainees' knowledge. ${ }^{6-11}$ On the other hand; many studies showed that students got better scores in PBL method..$^{3,12-15}$ So present study was taken up to know the teaching method which is preferred by the students for various disciplines in medical education by emphasizing on Pharmacology because of learning and remembering difficulty.

\section{Aims and objectives}

1. To know the best teaching methods with respect to each subjects.

2. To know the approach needed to include the appropriate learning methods to current teaching methods.

\section{METHODS}

Questionnaire based study was conducted to know the Perception of interns towards teaching methods among MBBS subjects: Problem based teaching versus traditional based teaching methods at Bidar Institute of Medical Sciences, Bidar after obtaining the permission from institutional ethical committee. Pre tested questionnaire was distributed to 80 intern's 2013 batch and the same was collected to analyse.

\section{Statistical}

Results obtained were tabulated and expressed in percentages using Microsoft excel and Microsoft world software.

\section{RESULTS}

Table 1: Phase I subjects.

\begin{tabular}{|llllllll|}
\hline S. no & Phase I subjects & LBL & $\%$ & PBL & $\%$ & Both & $\%$ \\
\hline 1. & Anatomy & 23 & 53.48 & 3 & 6.97 & 17 & 39.53 \\
\hline 2. & Physiology & 16 & 37.20 & 9 & 20.93 & 18 & 41.86 \\
\hline 3. & Biochemistry & 21 & 48.83 & 5 & 11.62 & 17 & 39.53 \\
\hline
\end{tabular}

Table 2: Phase II subjects.

\begin{tabular}{|llllllll|}
\hline S. no & Phase II subjects & LBL & \% & PBL & \% & Both & $\%$ \\
\hline 1. & Pharmacology & 10 & 23.25 & 10 & 23.25 & 23 & 53.48 \\
\hline 2. & Pathology & 13 & 30.23 & 8 & 18.60 & 22 & 51.16 \\
\hline 3. & Microbiology & 16 & 37.20 & 7 & 16.27 & 20 & 46.51 \\
\hline 4. & Forensic medicine & 13 & 30.23 & 11 & 25.58 & 19 & 44.18 \\
\hline
\end{tabular}

Table 3: Phase III Part I subjects.

\begin{tabular}{|llllllll|}
\hline S. no & Phase III Part I subjects & LBL & $\%$ & PBL & \% & Both & \% \\
\hline 1. & PSM & 10 & 23.25 & 5 & 11.62 & 28 & 65.12 \\
\hline 2. & ENT & 4 & 9.30 & 13 & 30.23 & 26 & 60.46 \\
\hline 3. & Ophthalmology & 6 & 13.95 & 10 & 23.25 & 27 & 62.79 \\
\hline
\end{tabular}

Table 4: Phase III Part II subjects.

\begin{tabular}{|lllllll|l|}
\hline S. no & Phase III Part II subjects & LBL & \% & PBL & \% & Both & \% \\
\hline 1. & Medicine & 2 & 4.65 & 16 & 37.20 & 25 & 58.13 \\
\hline 2. & Surgery & 2 & 4.65 & 14 & 32.55 & 27 & 62.79 \\
\hline 3. & Orthopedics & 3 & 6.97 & 12 & 27.90 & 28 & 65.12 \\
\hline 4. & Pediatrics & 2 & 4.65 & 13 & 30.23 & 28 & 65.12 \\
\hline 5. & Obstetrics \& Gynecology & 3 & 6.97 & 14 & 32.55 & 26 & 60.46 \\
\hline
\end{tabular}

$\%$ - percentage; numerical's below LBL, PBL \& Both - number of respondents

\section{DISCUSSION}

Out of 80 interns only $43(53.75 \%)$ returned filled questionnaire. Among 43 interns 25 (58.14\%) were males and $18(41.86 \%)$ were females.
Among phase I subjects i.e. anatomy, physiology and biochemistry; $53.48 \%$ and $48.83 \%$ were in favour of LBL for better and easy understanding of the concepts with respect to anatomy and biochemistry respectively. About $41.86 \%$ preferred both LBL and PBL for 
physiology. Of all the pre-clinical subjects' least favoured method was PBL (6.97\%) for learning anatomy (Table 1).

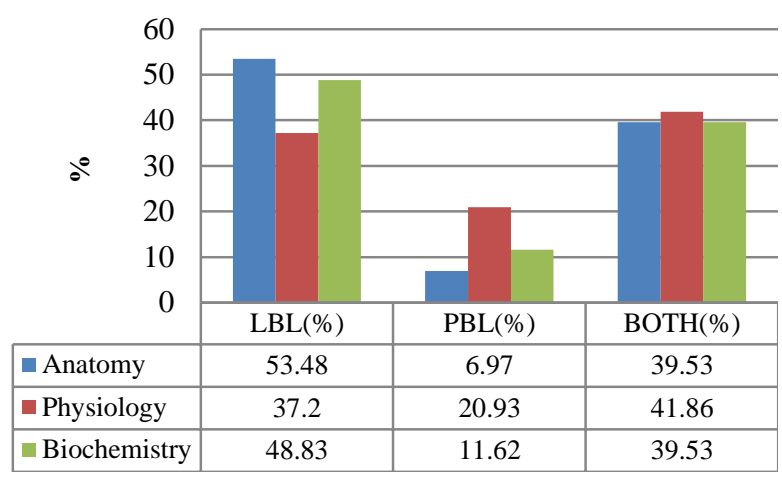

Figure 1: Phase I subjects.

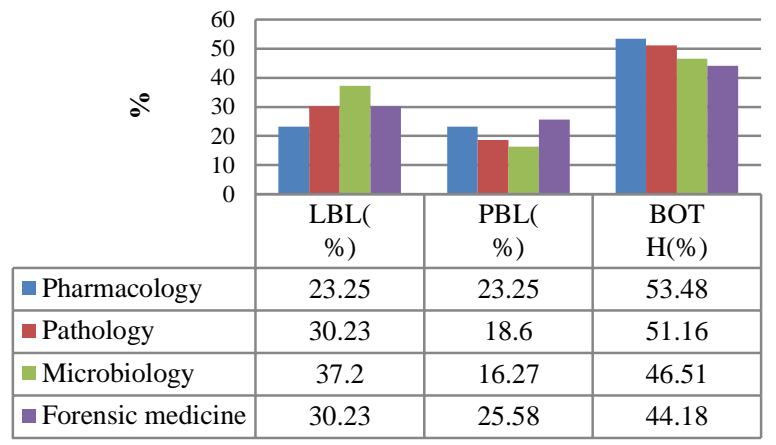

Figure 2: Phase II subjects.

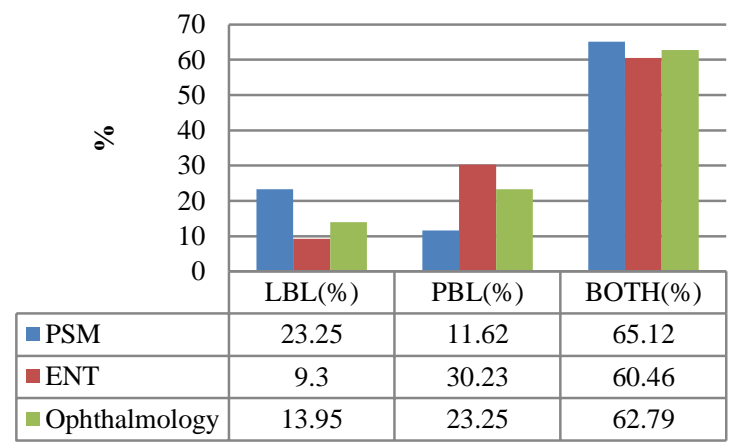

Figure 3: Phase III Part I subjects.

In case of Phase II subjects approximately $50 \%$ were towards both LBL and PBL methods simultaneously could be the appropriate way for getting in-depth knowledge in particular subjects, which form the core foundation/pillar during MBBS course. About 53.48\%, $51.16 \%, 46.51 \%, 44.18 \%$ of them were in favour of both LBL and PBL approach side by side for inculcating both theoretical aspects with practical or clinical thinking towards differential diagnosis and treating the same in a rationalized manner in pharmacology, pathology, microbiology and forensic medicine respectively (Table 2).
Among phase III part I and part II subjects approximately around $60 \%$ preferred both methods to be taken collectively while teaching respective subjects. $65.12 \%$, $60.46 \%, 62.79 \%$ preferred both methods for PSM, ENT and Ophthalmology respectively (Table 3).

But in case of phase III part II , approximately 58\% $65 \%$ were in favour of both approach with exception of only few were towards LBL (4.65\%-6.97\%) indicating that traditional based approach alone will leads to failure analysing the individual patients bedside. So the better way to avoid such things is to include PBL along with LBL, to have a crystal clear understanding of basic concepts and its utilization clinically probably helps future young budding doctors to have their individual analysing capacity while diagnosing and treating specific conditions (Table 4).

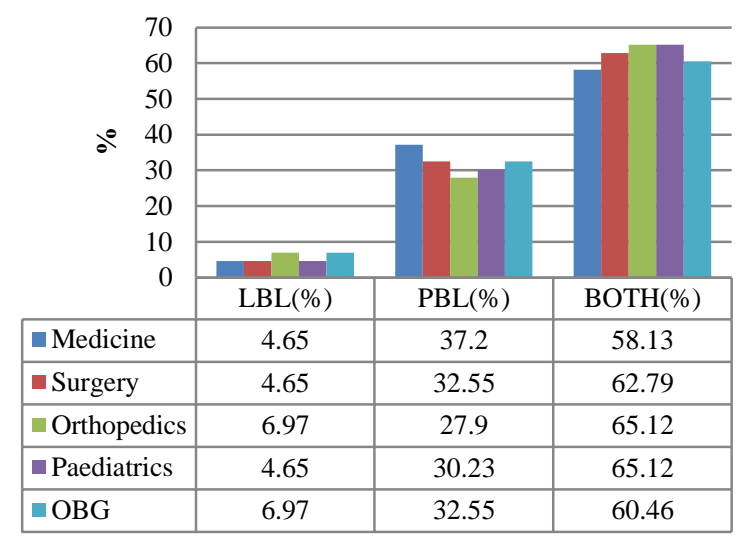

Figure 4: Phase III Part II subjects.

A study conducted on nursing students by Lin in Taiwan showed that the group who received PBL as the training method had more satisfaction, critical thinking and selfmotivated learning. And it also revealed that PBL training was more effective than conventional teaching. ${ }^{13}$

In our study students preferred more of LBL in $1^{\text {st }}$ year subjects. Among $2^{\text {nd }}$ year subjects equal importance was given for learning Pharmacology, i.e., PBL \& LBL simultaneously, and other subjects like pathology, microbiology and forensic medicine, LBL was preferred slightly over PBL. But the overall preference was to have both approach i.e., PBL along with the LBL for the better and effective acquisition of knowledge in coordination with practical aspects

A study on teaching methods in Shifa College of Medicine showed that $67 \%$ of the students wanted LBL and PBL going on side by side. ${ }^{16}$ Even in present study on an average $54.42 \%$ students preferred both LBL \& PBL methods side by side.

A cross-sectional study showed that $79 \%$ of the medical students liked PBL sessions which were in comparison to our study where PBL was slight edge over LBL and it 
was observed that PBL helped them in building up communication skills, interpersonal relationship and problem solving capacity to great extent. ${ }^{17}$

Maximum students expressed that comprehensive approach involving both LBL \& PBL leads to better understanding of subject and invoke self - learning habit among students.

This combined methodology helps the students to understand the subject in depth but the process of PBL conductance also inculcates self-learning practice among students as they have to formulate their learning goals \& objectives themselves after providing a PBL scenarios, solve the problem themselves by means of internet, consulting various books in library etc. and actively participate in group discussions which ultimately results in integrated mode of learning by going through all possible opportunities to solve them.

A similar study by Alam AY, et al also concluded that PBL along with LBL will promote independent and creative learning among medical students. ${ }^{16}$ This was similar to the present students perception.

Integrated way of learning was the most scientific approach which was preferred by students, that was in comparison with similar study, where 105 (72.4\%) students agreed with the significance of the subjects' integration in the clarification of concepts in medical studies. $^{18}$

Likewise, another study revealed that integrated curriculum promoted better understanding of health sciences pertaining to common diseases and majority of the respondents $(77.61 \%)$ expressed that PBL in modules assisted to great extent in interpreting the cases in their annual examinations. ${ }^{19}$

\section{CONCLUSION}

Appropriate modality of presentation of the problem could play a significant role in enhancing students' problem-solving skills in their fields, when training students, such abilities are one of the focuses on integration LBL with PBL curricula. Implementing PBL in the past, as well as in present is a providing challenge for PBL researchers and practitioners in provide opportunities \& new insights towards future discovery. Further research will provide intellectual and scientific support to inform and improve the practice of PBL as well as education in general. It was shown that PBL training was more effective than conventional teaching. Considering students' satisfaction, many studies showed that students prefer PBL preceded by LBL. For a more accurate comparison of these two methods with regard to knowledge retention, further studies are recommended.
Funding: No funding sources

Conflict of interest: None declared

Ethical approval: The study was approved by the Institutional Ethics Committee

\section{REFERENCES}

1. Wood DF. ABC of learning and teaching in medicine Problem based learning. BMJ. 2003;326(7384):328.

2. Onyon C. Problem-based learning: a review of the educational and psychological theory. Clin Teach. 2012;9(1):22-6.

3. Mc Parland M, Noble LM, Livingston G. The effectiveness of problem-based learning compared to traditional teaching in undergraduate psychiatry. Med Educ. 2004;38(8):859-67.

4. Kilroy DA. Problem based learning. Emerg Med J. 2004;21(4):411-3.

5. Dehkordi AH, Heydarnejad MS. The impact of problem-based learning and lecturing on the behavior and attitudes of Iranian nursing students. A randomised controlled trial. Dan Med Bull. 2008;55(4):224-6.

6. Smits PB, de Buisonje CD, Verbeek JH, van Dijk FJ, Metz JC, ten Cate OJ. Problem-based learning versus lecture-based learning in postgraduate medical education. Scand J Work Environ Health. 2003;29(4):280-7.

7. Carrero EJ, Gomar C, Fábregas N, Penzo W, Castillo J, Villalonga A. Clase magistral versus aprendizaje basado en caso/problema para la enseñanza del embolismo aéreo en formación médica continuada. Revista Española de Anestesiología y Reanimación. 2008;55(4):202-9.

8. Goodyear HM. Problem based learning in a junior doctor teaching programme. Arch Dis Child. 2005;90(3):275-8.

9. Khan H, Taqui AM, Khawaja MR, Fatmi Z. Problem-based versus conventional curricula: influence on knowledge and attitudes of medical students towards health research. PLoS One. 2007;2(7):e632.

10. Johnston JM, Schooling CM, Leung GM. A randomised-controlled trial of two educational modes for undergraduate evidence based medicine learning in Asia. BMC Med Educ. 2009;9:63.

11. Choi E, Lindquist R, Song Y. Effects of problembased learning vs. traditional lecture on Korean nursing students' critical thinking, problem-solving, and self-directed learning. Nurse Educ Today. 2014;34(1):52-6.

12. Tack CJ, Plasschaert AJ. Student evaluation of a problem-oriented module of clinical medicine within a revised dental curriculum. Eur J Dent Educ. 2006;10(2):96-102.

13. Lin CF, Lu MS, Chung CC, Yang CM. A comparison of problem based learning and conventional teaching in nursing ethics education. Nurs Ethics. 2010;17(3):373-82. 
14. Moreno-Lopez LA, Somacarrera-Perez ML, DiazRodriguez MM, Campo-Trapero J, Cano-Sanchez J. Problem-based learning versus lectures: comparison of academic results and time devoted by teachers in a course on Dentistry in Special Patients. Med Oral Patol Oral Cir Bucal. 2009;14(11):e583-7.

15. Anyaehie US. Comparative evaluation of active learning and the traditional lectures in physiology: a case study of 200 level medical laboratory students of Imo State University, Owerri. Niger J Physiol Sci. 2007;22(1-2):117-21.

16. Alam AY, Shah S. Faculty and students Survey: Methods of imparting knowledge suitable for undergraduate medical students. Pak J Med Res. 2003;42:116-9.
17. Habib F, Baig L, Mansuri FA. Opinion of medical students regarding problem based learning. J Pak Med Assoc. 2006;56:430-2.

18. Khoshnevisasl P. Comparison of Problem-based Learning With Lecture-based Learning. Iran Red Crescent Med J. 2014;16(5):e5186.

19. Jaffri N, Huda N, Jaleel A. Integrated undergraduate curriculum at Ziauddin University. JIIMC. 2009;5:7.

Cite this article as: Padmanabha TS, Manu G, Savkar MK, Chandrakantha T, Neha K. Student's perception towards learning medical sciences: problem based teaching versus lecture based teaching methods. Int $\mathbf{J}$ Basic Clin Pharmacol 2016;5:411-5. 